\title{
Medicina, política y bien común: 40 años de historia del programa de control de la tuberculosis (1973-2013)
}

\author{
Marcelo López-Campillay ${ }^{1 *}$
}

\section{Nota del Editor:}

Marcelo López Campillay es Doctor en Historia e Instructor Adjunto del Programa de Estudios Médico Humanísticos de la Facultad de Medicina de la Pontificia Universidad Católica de Chile. Su línea de investigación aborda la historia de la salud y la enfermedad, siendo su tema principal el estudio de la tuberculosis. En esta oportunidad nos ofrece una reseña bibliográfica de su libro lanzado en octubre de 2015, primero de la serie "Hitos de la Salud Pública en Chile", cuyo objetivo es preservar la memoria histórica y registrar las buenas prácticas de la Salud Pública chilena.

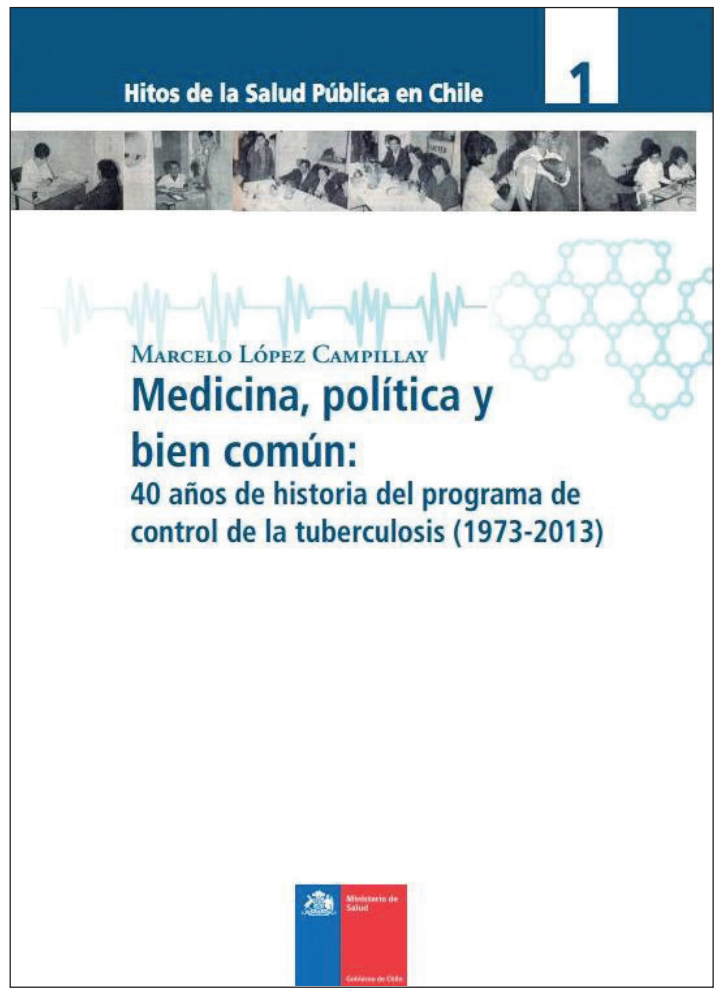

Fecha de envío: 19 de octubre del 2015 - Fecha de aceptación: 29 de octubre del 2015
En el mes de enero del año 2014, acepté una invitación extendida por el MINSAL a través del Departamento de Enfermedades Transmisibles y la Unidad de Patrimonio Cultural de la Salud, para participar en la redacción de un libro que ilustrara las cuatro décadas de vida del Programa de Control de la Tuberculosis, una de las políticas icónicas de la Salud Pública chilena en el siglo XX. En razón de la experiencia acumulada en el Programa de Estudios Médicos Humanísticos en torno a la investigación histórica de la tuberculosis en Chile, decidí acoger el desafío por cuanto consideré que tenía frente a mí una experiencia de aprendizaje sobre una etapa particular del itinerario histórico de la lucha contra la denominada peste blanca en nuestro país, la cual hasta entonces no habíamos abordado. La apuesta se cumplió plenamente.

El desafío investigativo fue doblemente motivante, por cuanto por un lado aspiré a posicionar la perspectiva histórica como un instrumento de análisis de una política social, $y$, por otra parte, tuve que determinar una metodología particular para cumplir con el trabajo de investigación. Así, en el inicio de esta tarea se acordó sostener la investigación a partir de una serie de entrevistas con un grupo de profesionales de la salud de diversas áreas (medicina, enfermería, tecnología médica) que en distintas formas y en determinados momentos históricos habían participado en la gestación y desarrollo del programa. Dentro de las conversaciones preliminares establecidas para la planificación de la investigación que debí llevar adelante, emergió un rasgo que se transformó en

1) Programa de Estudios Médico Humanísticos, Facultad de Medicina, Pontificia Universidad Católica de Chile.

*Autor de Correspondencia: malopez@uc.cl 
una suerte de faro que iluminó la narración. En efecto, asomó la voluntad de rescatar el rango pedagógico que en materia de Salud Pública había cristalizado el programa a lo largo de su trayectoria, una virtud que en mayor o menor medida todos los entrevistados subrayaron. Sobre esa premisa inicié la serie de entrevistas en marzo del año 2014, trabajo que culminé a fines de ese año.

Paralelamente, con el apoyo de una ayudante de investigación, Miriam Beltrán, realicé una revisión de algunas fuentes existentes en las bibliotecas médicas de la Pontificia Universidad Católica y Universidad de Chile, la Biblioteca Nacional y el Archivo Nacional. La finalidad de esa tarea fue complementar los testimonios que los médicos, enfermeras y tecnólogos brindaron a fin de ir reconstruyendo el camino que se siguió para bosquejar el programa y conocer también los obstáculos que, sobre un contexto local y global, debieron sortear para condensar en una propuesta técnica y política una serie de ideas que aquellos profesionales aprendieron en sus respectivos contextos históricos.

La narración de la historia se elaboró a partir de dos etapas bien definidas cuyo hito divisorio fue el año 1973. La primera se circunscribe a la década de 1950 y en ella puede constatarse un trabajo que apuntó a modelar un esquema de lucha antituberculosa que superara la modalidad que había regido hasta entonces, la cual se había ido amalgamando desde comienzos de siglo XX. En este proceso habían convergido una pluralidad de entidades y acciones, tales como el concurso de instituciones estatales y privadas, la vacunación BCG, la medicina preventiva, el trabajo interprofesional realizado por médicos, enfermeras sanitarias y visitadoras sociales, el desarrollo del sanatorio antituberculoso y las Gotas de Leche, entre las principales. Sus resultados concretos siempre fueron discutibles toda vez que se tenía conciencia de la complejidad del problema y que cualquiera que fuese la solución demandaba una mirada a largo plazo.

El escenario se modificó profundamente a partir de 1950, cuando una serie de circunstancias se conjugaron para fundir un nuevo enfoque y una nueva estrategia antituberculosa. La primera de ellas, la irrupción de las "drogas que hacen milagros", los antibióticos, una solución que marcó una nueva era en la historia de la medicina a nivel mundial y en la historia de la tuberculosis. La segunda, la creación del Servicio Nacional de Salud (SNS) en el año 1952, la entidad político-técnica que puso fin a la dispersión previa de esfuerzos institucionales en materia sanitaria y concentró en una sola iniciativa pública capaz de extender a todo el país y de manera solidaria, vía gratuidad, cualquier tratamiento que tuviese como finalidad la erradicación de las enfermedades sociales, además de desarrollar políticas de prevención. Y, en tercer término, la existencia de una generación de profesionales que fue capaz de conjugar en forma virtuosa todos esos elementos para dar vida a una fórmula que fue la piedra angular de la política moderna contra el bacilo de Koch, esto es, el tratamiento triasociado y supervisado de la tuberculosis.

Así, en el transcurso de la década de 1960 se fueron reuniendo las piezas necesarias para que se adoptara un nuevo esquema terapéutico a gran escala. Una de las claves que explica la particularidad histórica del programa de control de la tuberculosis fue, precisamente, el trabajo que se desarrolló a partir de las experiencias que realizaron en el Hospital San Juan de Dios y su anexo, el Centro de Enfermedades Broncopulmonares. A partir de esta labor, se pudieron ir haciendo los ajustes necesarios para poder implementar eficazmente la innovación que representaron las drogas antituberculosas, hecho que deja en evidencia una enseñanza histórica, a saber, que no es suficiente recibir los últimos progresos de la terapéutica moderna si no se posee la capacidad para distribuirlos eficientemente a toda la población.

Nuestro país tuvo la oportunidad de comprobar que ese ideal fue factible de materializar. La empresa antituberculosa tuvo como apoyo fundamental, por un lado, la red de laboratorios que se fue construyendo en torno a Instituto de Bacteriología, posteriormente Instituto de Salud Pública, y por otra parte la existencia de un conjunto de centros científicos en el plano internacional que permitió a varios profesionales chilenos renovar sus conocimientos en bacteriología para replicarlos en la elaboración del nuevo modelo terapéutico. De este modo, para el año 1973 se determinó que existían las condiciones políticas, administrativas y la experiencia terapéutica necesaria como para institucionalizar el nuevo paradigma antituberculoso, el cual germinó en el gobierno del presidente Salvador Allende y que condensó casi 20 años de preparación. En ese instante nació oficialmente el Programa de Control de la Tuberculosis que, desde el punto de vista histórico, simultáneamente fue un punto de llegada y un punto de partida.

A partir de entonces la Salud Pública chilena inauguró una segunda etapa en su lucha contra el bacilo, teniendo plena certeza que, por primera vez en la historia del país, existía un método probado para erradicar a una de las endemias sociales por antonomasia. La nueva política antituberculosa fue sometida a prueba en virtud de las nuevas condiciones políticas que vivió el país a partir del golpe de Estado del año 1973, y, especialmente, a partir de la serie de reformas que la Junta Militar aplicó en la esfera de la Salud Pública a fines de esa década. Pese a las ásperas diferencias políticas que surgieron entre un sector importante de miembros del programa de control de la tuberculosis y el nuevo gobierno, primó finalmente el convencimiento de que el modelo debía mantener su base científica y solidaria ante la tentativa que existió a fines de la década de 1970 de imponer la obligación de un pago a quienes accedieran al 
tratamiento. En esta defensa de los pilares del programa, indudablemente, influyó el papel de personalidades del mundo médico que, más allá de las diferencias ideológicas que podían existir entre ellos en un momento difícil para la convivencia social en Chile, estaban convencidos de que el camino para combatir exitosamente la tuberculosis era el que se había trazado en la década anterior, tal como lo evidenciaban las estadísticas.

Al comenzar la década de 1990, el Programa de Control de la Tuberculosis entró en una nueva fase histórica, enmarcada en un proceso de cambios nacionales e internacionales o globales. Junto con el nuevo enfoque epidemiológico que se comenzó a desplegar a partir del año 1994, se apuntó definitivamente a la consecución de la erradicación de la enfermedad como problema de salud pública, una propuesta que solamente podía ser fruto de una trayectoria que anotaba sustanciales progresos. No obstante, la nueva perspectiva que se pretendió aplicar para conseguir la evolución del programa debió afrontar un contexto que en mayor o menor medida marcó nuevos desafíos para los equipos de trabajo que integraban el programa. Por un lado, el escenario global asignó a la tuberculosis y otras enfermedades infecciosas el estatus de enfermedades emergentes o reemergentes. Por otra parte, la transformación de Chile en un polo de desarrollo económico se convirtió en una oportunidad para que arribaran al país personas provenientes de países donde la tuberculosis es un problema de salud pública de una mayor relevancia, fenómeno ante el cual el personal del programa debió reaccionar. Al mismo tiempo, en el plano local, el programa debió hacer frente a una situación paradójica. Debido a las buenas cifras epidemiológicas que ofreció su trabajo, las autoridades de la época estimaron que existían otras prioridades que atender con parte de los recursos que se asignaban al trabajo antituberculoso. Vale decir, el programa de control de la tuberculosis debió hacerse cargo de las consecuencias de sus progresos, en circunstancias de que acorde con la meta fijada, se requería de una financiación constante que permitiera asegurar el objetivo señalado. Así, desde ese instante hasta la primera década del siglo XXI, se fueron generando diversos episodios marcados por encuentros y desencuentros entre la dirección del programa y el Ministerio de Salud, los cuales respondieron a las diferentes expectativas que surgieron desde los sectores involucrados, las que también pueden reflejar diferentes visiones generacionales en torno a cómo desarrollar políticas de salud.
¿Qué oportunidades de aprendizaje ofrece la historia de esta iniciativa modélica de la historia sanitaria chilena? La primera es a todas luces la suerte de escuela de Salud Pública que ha conformado el programa de control de la tuberculosis. Si nos ceñimos a la lectura de su historia podemos observar cómo se integraron el trabajo multidisciplinario, la aplicación a gran escala de conocimiento científico de punta y la convicción de que la difusión de la nueva terapia fue una de inclusión social. Por ello, como segunda consideración que conviene señalar es la importancia que posee la Salud Pública en la formación de pregrado y que, según se desprende de lo enunciado por las personas que entregaron su testimonio sobre su experiencia profesional en el programa, en las últimas décadas sufrió un declive producto del desarrollo de modelos educativos que privilegiaron otros objetivos formativos, todo lo cual ha repercutido en la capacidad del sector público para responder a la demanda de atención médica de la población.

Desde mi óptica, no queda sino agradecer esta experiencia formativa que facilitaron quienes dirigen el Departamento de Enfermedades Transmisibles y la Unidad de Patrimonio Cultural de la Salud. Especialmente, rescato la posibilidad de hacer del análisis histórico una herramienta que allana el camino a la valoración del itinerario de las políticas de salud en Chile y que incentiva la presente discusión pública sobre cuestiones centrales relativas al proyecto de desarrollo que deseamos para el país, donde la salud, como ha ocurrido desde hace más de dos siglos, desempeña un papel fundamental. En definitiva, la lectura de la historia del Programa de Control de la Tuberculosis es un verdadero documento educativo que invita a las nuevas generaciones a ponderar el valor histórico de la salud como un bien por el cual debe velar toda la sociedad.

\section{Referencias}

López-Campillay, M. (2015). Medicina, Política y Bien Común: 40 años de Historia del Programa de Control de la Tuberculosis (1973-2013). Santiago de Chile: Ministerio de Salud. 